\title{
LAS ISLAS VIVAS: SICILIA, CONSTANTINOPLA Y CERDEÑA EN EL RECUERDO LITERARIO DE JULIÁN MEZA Luzelena Gutiérrez de Velasco*
}

Viajar es una forma de abrir el mundo. Cuando viajamos, experimentamos el vértigo de la pérdida de toda seguridad y, por ello, lo familiar se borra para dar paso a lo inusual, a lo extraño, a lo exótico. Viajar es también un proceso para fracturar las fortalezas y comodidades del viajero, que se remitirá en cada momento a su punto de partida, como el espacio de las comparaciones; también como el lugar de las certidumbres.

Pero viajar y recordar, viajar y generar una escritura con las peripecias del recorrido origina una modalidad literaria: el relato de viajes, que se tiñe de las características de la narrativa de aventuras, se aproxima a la reflexión y se cubre con los enigmas de la escritura de la espacialidad. Escribir para redescubrir el desplazamiento en el espacio; escribir para mantener la memoria del viaje; escribir para rememorar al yo que se confunde con el paisaje y aprende a ser otro en el contacto con lo ajeno, con lo extranjero.

Así Julián Meza, el novelista, el ensayista, el historiador, el viajero se propone una aventura de vida: desplazarse por el mundo para ir en busca de sus propios orígenes. En el Mediterráneo encuentra la fuente de esa fascinación que lo atrae y, a semejanza de Marco Polo, se deja atrapar, aunque éste va hacia el Oriente y Julián Meza fluctúa en el Mare Nostrum. O como otro viajero, Hermann Hesse, que en su Viaje a Oriente nos cuenta la experiencia del viaje hacia sí mismo, hacia el descubri-

*El Colegio de México. 
miento de lo insospechado. En el fondo de la búsqueda de Julián Meza no se vislumbra la convicción de la tierra sino la fantasmagoría de la insularidad; porque las islas se desdibujan en la bruma y se perfilan como espacio de la imaginación, de la creatividad y de la historia. El Mare Nostrum guarda esos tropiezos, esos fragmentos, esos retales, que, sumados, conforman un sueño: el sueño del espacio que se expande hacia el recuerdo y hacia la historia.

Ya años antes, el historiador Fernand Braudel se había enamorado y comprometido con el Mediterráneo para regalarnos "otra” forma de aproximarse a la historia:

Tanto en su paisaje físico como en su paisaje humano, el Mediterráneo es una encrucijada; el Mediterráneo extravagante aparece, no obstante, en nuestros recuerdos como una imagen coherente, como un sistema donde todo se mezcla y se recompone en una unidad original. ¿Cómo explicar esta unidad evidente, este ser profundo del Mediterráneo?"1

Tal parecería que Julián Meza, obediente a este mandato, se embarca en la búsqueda de esa unidad que no podemos advertir debido a la bruma, la fragmentación de las islas, el cruce cultural, la encrucijada ideológica, etc. Viaja y escribe, corrige y nos entrega la recomposición de los fragmentos que su memoria recupera del olvido, de la borradura que la vida impone con el paso de los días. El relato de viajes se inviste de la urgencia por rescatar lo perdido y toma cuerpo, hasta ahora, en tres libros: Sicilia. La piedra negra (2008), Constantinopla, la isla del mediodía (2011) y Cerdeña. La isla de Eolo (en prensa). ${ }^{2}$

En estos textos, el autor se ha propuesto una dura y dulce tarea: evitar toda relación con la esperada guía turística, porque deslinda de manera implacable el viajar del simple turismo, que considera una plaga insoportable de nuestra época. Por ello, frente a la pregunta "¿qué clase de libro sería?" responde con firmeza:

[S]ería un libro de viajes que no fuera un libro de viajes, un libro de historia que no fuera un libro de historia, un libro donde la ficción desem-

${ }^{1}$ El Mediterráneo. El espacio y la historia, 1989, México, FCE, trad. de F. González Aramburo, p. 10.

${ }^{2}$ En adelante se citarán en el texto entre paréntesis por el nombre geográfico y el número de página. 
peñara un papel importante sin tratarse, en sentido estricto, de una ficción. Sería, en síntesis, un libro de retales donde estarían presentes los viajes, el ensayo, la historia, la ficción (Sicilia, 17).

Lo que Julián Meza escribe para Sicilia vale para los otros dos libros, aunque cada uno posea una tendencia particular. Podemos afirmar que Sicilia es el laboratorio donde se ponen a prueba las limitaciones del género literario, el relato de viajes; Constantinopla se inclina con mayor esmero hacia el costado histórico y Cerdeña se deja enmarañar más en las redes de lo antropológico, en la conformación de un paisaje humano, en la intromisión del yo narrador. Aunque, finalmente, en los tres libros confluyen las modalidades de escritura que el escritor se ha trazado como derroteros: la historia, los viajes y la ficción.

Ante la selección de modelos, el autor no duda con respecto a los textos que deben ser eliminados por su retórica excesiva, por su apego a la mera descripción geográfica, por la construcción de espacios ideales; así se rechazan los relatos a la manera de Pierre Loti, de Goethe en su viaje a Italia, y se eligen los caminos marcados por Montaigne, Hofmannsthal, Álvaro Mutis y Cees Nooteboom. Con todo, la pauta fundamental la proporciona sin duda Italo Calvino con Las ciudades invisibles, en donde la memoria y la imaginación se conjugan para dar origen a una multiplicidad de ciudades con nombre de mujer y en las que se corporiza el deseo, los signos, los trueques, la muerte, la vida... Las palabras de ese libro inmarcesible ofrecen el epígrafe para Sicilia: "Hay que guardarse de decirles que a veces ciudades diferentes se suceden sobre el mismo suelo y bajo el mismo nombre" (Sicilia, 9). Y detrás de cada página de los tres libros de Julián Meza subyace la necesidad de "descubrir las razones secretas que han llevado a los hombres a vivir en las ciudades, razones que puedan valer más allá de todas las crisis", como señala Calvino. ${ }^{3}$

Descubro además otros modelos ocultos e innominados en los textos de Julián Meza; me refiero a Antonio Tabucchi y sus exploraciones por las islas Azores, sobre todo en Dama de Porto Pim, libro en el que Tabucchi engarza la idea del viaje con la reflexión literaria, con la sensible captación de los hombres y mujeres sencillos que viven y

${ }^{3}$ Las ciudades invisibles, 1995³, Madrid, Siruela, trad. de A. Bernárdez, p.15. 
trabajan en las islas, los cazadores de ballenas, los poetas olvidados. Porque Tabucchi da con una clave fundamental, nos dice "he comprendido que el Occidente no tiene fin sino que sigue desplazándose con nosotros, y que podemos perseguirle a nuestro antojo sin jamás alcanzarle". ${ }^{4}$

Como este autor, Julián Meza se pregunta por los límites geográficos y sabe que éstos se extienden y desplazan de acuerdo con los acontecimientos de la historia. Va a Turquía en busca de Constantinopla y no de Istambul (que no Estambul). Explora el pasado en el presente. Se adentra en las ruinas para descubrir las ciudades. Percibe con pasión de viajero la superposición de las culturas: fenicia, griega, bizantina, lombarda...

Por su parte, Ottmar Ette en su iluminador estudio sobre este tipo de relatos: Literatura de viaje. De Humboldt a Baudrillard, afirma que "La fascinación del relato de viajes [...] se basa fundamentalmente en los movimientos de entendimiento omnipresentes en la literatura de viajes, considerados como movimientos de entendimiento en el espacio. ${ }^{5}$ Esta comprensión del espacio como lugar de los "movimientos de entendimiento" se relaciona de manera clara con la visión de Julián Meza sobre los lugares y su interrelación con el viajero, en tanto se despliegan las condiciones que hacen de él un individuo que abarca el espacio en un sentido que supera el mero recorrido; no se trata de ir de un lugar a otro, ni de cumplir con un itinerario planeado, ni de devorar kilómetros, sino de descubrir en el espacio el paso del tiempo y simultáneamente poder imaginar esos lugares, múltiples y variopintos, en la superposición de capas espaciotemporales. Por eso, el escritor entiende que:

Viajar no es trasladarse, ir de un lado a otro como saca de correos o voluminosa maleta atiborrada de ropa o de perfumes. Debido a la escasez de tiempo uno dejará de observar mucho de lo que quiere, pero no sólo no puede acercarse a todo, sino que la mejor manera de ver es casi siempre avara" (Sicilia, 94).

Asimismo, puede establecerse que el viaje no es un tema novedoso en la producción literaria de Julián Meza, sino que se descubre en sus

${ }^{4}$ Dama de Porto Pim, 1987, Barcelona, Anagrama, trad. de C. Artal, p. 9.

${ }^{5}$ 2001, México, UNAM-DAAD, p. 14. 
novelas y en sus ensayos como un anhelo constante. La huella del conejo es de hecho el relato de un viaje en sentido inverso al viaje que los lectores conocemos. Los colonnautas, comandados por el Almirante, recorren el mundo en busca de mejores tierras y él intuye que "la tierra era monda y desnuda como una naranja, pero a menudo se dejaba arrastrar por el escepticismo y decía para sus adentros: 'Al frente, el abismo; atrás, el precipicio"'. ${ }^{6}$ Frase en la que encontramos la naturaleza crítica del "movimiento de entendimiento", porque supone el desplazarse pero se anula la idea de avance o aproximación al lugar.

Contra todo lo previsto, los tres relatos de viaje de Julián Meza pueden aportarnos las delicias de la visita a esos lugares impregnados por la historia: Sicilia, Constantinopla o Cerdeña. Son espacios no comunes en los recorridos turísticos. En el primer viaje, se elige un movimiento circular porque el periplo se realiza entre Palermo y, en una vuelta contraria a las manecillas del reloj-retrasando el tiempo-, se llega de nuevo a Palermo. Las paradas conforman los breves fragmentos, los capítulos que constituyen los libros. En el caso de Constantinopla, se trata de un segundo viaje, uno sugerido por el escritor Álvaro Mutis, que recomienda al viajero poner de relieve la ciudad de Constantino en las entrañas de la ciudad turca, signada por el pasado otomano. Es decir, nos enfrenta a un viaje en profundidad con un movimiento de descenso. Así, nos confiesa Meza: "Mi regreso a Constantinopla está marcado por el afán de vivir lo no vivido y ver lo no visto" (Constantinopla, 41). Aunque la antigua y gran ciudad se ha esfumado, el viajero sabe que: "Por más desaparecido que esté, ese ayer pervive en mi imaginario junto con los dioses que como una tempestad abandonaron para siempre un mundo desacralizado" (ibid., 44). En Istambul está grabada Constantinopla. El movimiento que se produce es de superposición de capas, de ciudades fusionadas.

Cerdeña implica un movimiento lento desde el exterior: los preparativos y Roma, la oposición al relato de Vittorini, para llegar a la isla y de allí a las construcciones nuraghi. Es como entrar en un laberinto, porque la historia y el paisaje de esta región son bastante desconocidos para el turismo tradicional, entonces hay que rodear para poder arribar.

${ }^{6}$ 1991, México, Vuelta, p. 24. 
De manera que la incursión mediante la escritura zigzaguea con suavidad como las olas en un día tranquilo. En un ir y venir entre la literatura y el relato histórico se inicia la exploración de un espacio hermoso pero agreste. En este viaje se hace una mayor insistencia en el recuerdo, en la reflexión literaria: Céline, Kundera, Homero, Virgilio y muchos más. Sin embargo, acompañamos al viajero a Porto Torres, a Tharros, a Oristano, a Saccargia.

Los tres viajes, las tres islas (Constantinopla también aparece como una isla en el Imperio romano), asimismo los tres libros de Julián Meza, se entrelazan para dar forma a una constelación insular. En una isla se rememora otra, y una prefigura a la siguiente. Algo similar ocurre con el manejo del tiempo, porque de la fuerte atracción del presente con las variadas descripciones del paisaje, la comida, las costumbres se gira hacia el pasado; el viajero-escritor se convierte entonces en un historiador que no quiere dejar pasar la oportunidad de situar el espacio en el tiempo. Las preguntas sobre la historia de cada ciudad, de cada lugar evaden el relato histórico tradicional para imbricarlo con la historia del presente. Se destaca el momento de la fundación de las ciudades, el relato de sus guerras e invasiones, pero cobra una mayor importancia el trazado de la línea que comunica el pasado con el hoy de esos espacios visitados: "Fueron modelados por Byzancio muchos de los pueblos que hoy habitan el Oriente de Europa, y la Grecia actual le debe más a Byzancio que a la Atenas de Pericles y de Fidias" (Constantinopla, 48). En la prosa de Julián Meza encontramos la virtud de otorgar a cada espacio y tiempo la tonalidad y el sabor que les corresponde en la realidad, en su memoria y en la imaginación que despierta en nosotros, sus lectores. Cuando parece que el relato está a punto de naufragar como página de libro de historia: "La Italia bizantina es invadida por los lombardos. Los ávaros, instalados en Europa central, incursionan en los Balcanes y sitian Constantinopla en 626", entonces irrumpe la descripción poética de un espacio o la reflexión se inclina hacia el yo del viajero que se queja del presente o rechaza su punto de partida, la Ciudad de México, o también se deleita con un helado de pistacchio, como en Cefalú.

La historia adquiere una densidad especial porque acompaña la visita de los espacios. A partir del lugar, la memoria histórica se 
pone en movimiento y, en el lugar, se instaura el monumento: templo, catedral, palacio, capilla, piscina de arena, fortaleza nuraghi, mezquita, etc. Con Julián Meza nos adentramos en el pasado de manera amena $\mathrm{y}$, donde los guías despistados no ven nada o sólo una vía rápida, el viajero se detiene ante la historia:

Lo importante era pararse junto a lo que queda de una muralla que iba del Mar de Mármara al Cuerno de Oro, pues medía seis mil seiscientos cuarenta y seis metros de largo (Constantinopla, 46).

Al relato de viaje, caracterizado por la descripción del espacio, la ciudad, y su historia, se une el relato del viaje hacia adentro. En los tres libros de Julián Meza testimoniamos la temperatura anímica del autor, nos convertimos en sus cómplices en las mil mañas del viajero, en el rechazo del turismo adocenado, en la sorpresa por los fulgurantes descubrimientos. En cierta forma, la figura del lector, del compañero de viaje, se encuentra encarnada en Philareti / Filareti, la amiga e interlocutora, que disfruta la belleza del paisaje, el calor del sol, la felicidad de los baños marinos y se deja asustar por las historias de mafiosos, como en Messina cuando: "Sin que me entere, Filareti edifica una barricada frente a la puerta de la habitación con todo lo que halla a la mano: una mesa, una silla, nuestras pequeñas maletas" (Sicilia, 102).

El viaje interior explora los sentimientos que produce el espacio en el presente, en el pasado del viajero. El relato de viajes se transforma así en autobiografía y nos muestra las modificaciones del yo narrador en contacto con la otredad. Podemos advertir cambios de humor desde el disgusto, por las mentiras de los guías, por algunos contratiempos y fallas en los itinerarios, al placer del encuentro con la historia en las ruinas, en las ciudades, en las fuentes, como la de Areusa; también se pone de manifiesto su necesidad del viaje como una forma de huida, como un evitar el presente que agobia. Por ello, el futuro se abre como una posibilidad del viaje que espanta a la muerte:

Pensar en Cerdeña me permite vivir fuera de la sucia realidad de un mundo que me mata. Cerdeña es mía porque así lo quiero, aun cuando 
sé perfectamente que no es mía porque lo propio es lo que no se puede uno apropiar; ¿cuándo volveré a Cerdeña? No lo sé, pero estoy convencido de que me espera, de la misma manera que me espera Sicilia y casi como Penélope esperaba a Ulises. (Cerdeña).

Julián Meza encuentra la vida en ese "movimiento de entendimiento" que inaugura el viaje y, por ello, escribe para consolidar la memoria de las ciudades, visibles e invisibles; para recuperar una historia que se nos olvida por el peso de tradiciones tan fuertes como la cristiana, que se opone a mirar de frente a sus opositores; finalmente, para dejarnos asomar a sus deleites como viajero y para compartir con nosotros la amistad de Philareti. No menos importante, pero sin duda destacable, resulta el que las islas vivas nos dan la oportunidad en estos textos de develar una teoría del viaje y profundizar en el sentido del viajar. 